EMBRYARIDDLE
Aeronautical University

SCHOLARLY COMMONS
International Journal of Aviation, Aeronautics, and Aerospace

$11-7-2016$

\title{
Stress Coping Strategies in Indian Military Pilots-Preliminary Observations
}

Catherine Joseph

Institute of Aerospace Medicine, Bangalore, India, csgeorge09@gmail.com

Follow this and additional works at: https://commons.erau.edu/ijaaa

Part of the Other Psychology Commons, and the Other Social and Behavioral Sciences Commons

\section{Scholarly Commons Citation}

Joseph, C. (2016). Stress Coping Strategies in Indian Military Pilots-Preliminary Observations. International Journal of Aviation, Aeronautics, and Aerospace, 3(4). https://doi.org/10.15394/ ijaaa.2016.1147

This Article is brought to you for free and open access by the Journals at Scholarly Commons. It has been accepted for inclusion in International Journal of Aviation, Aeronautics, and Aerospace by an authorized administrator of Scholarly Commons. For more information, please contact commons@erau.edu. 


\section{Stress Coping Strategies in Indian Military Pilots-Preliminary Observations}

\section{Cover Page Footnote}

The author is grateful to Prashanth Ayenger for help in some of the data collection. 
Military aviation is a high-stress occupation. As a result, military aircrew are exposed to a wide range of stressor events as part of military training and later operational requirements. When these requirements extend to actual war scenarios, flying missions with their often violent, unpredictable and unforgiving consequences may become highly stressful for air warriors. Stress coping is an important psychological construct which moderates/mediates the relationship between stressors and behavioral outcomes such as flying performance. In the occupational sphere of aircrew functioning, stress coping strategies are related to crew interaction styles and therefore are of relevance to CRM. Coping may also be linked to how cognitive challenges in the aviation environment are handled, determining various degrees/levels of cognitive adaptation which influence aeronautical adaptability, situational awareness and aeronautical decision making (Fornette et al. 2012).

In the clinical sphere of functioning, coping is an important variable in psychological/psychiatric consequences of stress and combat such as anxiety, fear of flying, motion sickness, Post-Traumatic Stress Disorder (PTSD) or depression (Stetz et al. 2007). These may lead to a spectrum of pervasive effects and deterioration in both performance and health. Substitution of maladaptive coping with more adaptive coping is an important component of therapeutic interventions and prognoses. These interventions include critical incident stress debriefing usually utilized after military deployment, aircraft accidents, incidents (e.g. ejections), and stress inoculation training and stress management techniques. In addition, cognitive behavior therapy in the management of motion sickness, fear of flying, or depression may be parts of these processes (Chung, 2006; Dobie \& May, 1994; Foreman, Bor \& van Gerwen, 2006; Meichenbaum, 2007; Mitchell, 2006; Morse \& Bor, 2006; Petrie, 2006; Stahl, 2004).

\section{Literature Review}

\section{Psychological Stress and Appraisal}

Some factors determine the individual overall physical health and baseline physiological resilience to stress. From a psychological perspective, the person's response to a stressor is mediated by both the appraisal of that stressor as well as the individual's "vulnerability" or susceptibility to the stressor. Factors like underlying personality, psychological needs, coping resources and styles determine the two processes.

Often the coping process is subjectively affected by the appraisal of a potential stressor. A primary appraisal consists of an evaluation of possible adverse or positive consequences where factors like harm/loss, threat or challenge are determined (Folkman \& Lazarus, 1980). A secondary appraisal consists of the evaluation of how 
the situation can be managed using personal or social resources. When physical or psychological damage is already done to a person, the stressor appraisal involves harm or loss. Threat appraisal involves evaluation of expected harm/loss that could be brought about by the stressor; as also the possibility of future impacts in case harm or loss is already done. When there are expected benefits or positive growth after the stress encounter, it is categorized as a challenge appraisal.

\section{Stress Coping Strategies}

One of the primary ways in which appraisal influences resilience to stress is through the development of effective stress-coping strategies. Coping strategies involve behavioral and psychological efforts that individuals use to overcome, accept, diminish or minimize internal and external stressors. Coping strategies involve problem-solving and emotion-focused methods. The problem-solving strategy involves one's active involvement in reducing stressor effects. This process involves assessing the situation for other options, coming up with a strategy and acting upon it and then evaluate the results. Emotion-focused coping strategy involves attempts to control emotional concomitants of stressors or potential stressors. According to research, different strategies are employed by individuals to deal with most stressful events. The type of stressor and individual coping style partly dictates which of these two strategies is adopted in which situation. Studies have shown that both types of coping strategies are used by the Indian population. Their effectiveness could be owing to the availability of a wider range of options to choose from and their flexibility in use. Also, coping behaviors associated with psychological distress were mainly emotion-focused (Rao, 1997).

Studies on coping have also distinguished between active and avoidant coping methods. Whereas coping mechanisms involve behavioral or psychological responses aimed at altering the nature of the stressor itself or changing one's perception of it; avoidant coping strategies make people take refuge in other behaviors such as alcohol use or various defense mechanisms, without confronting the actual stressors. These mental or defense oriented mechanisms serve the purpose of self-protection from emotional turmoil rather than sorting out the problem. There are two types of defense mechanisms i.e. weeping, repeating oneself and mourning and secondly the ego defense mechanisms such as denial and repression. Both behavioral and emotional (active coping) strategies are understood to be more efficacious in handling stress than avoidant coping strategy which is a psychological risk factor leading to negative responses to stressors (Holahan \& Moos, 1987). 


\section{Stress Coping Mechanisms in Aviators}

There have been several empirical efforts to describe the typical stress-coping styles of pilots. In one of the first, Fine and Hartman (1968) found that pilots predominantly coped with disruptive emotion and life crises by seeking constructive solutions. Somewhat less common, but nevertheless utilized processes were arguing, joking and ignoring the situation. Only rarely did pilots in their sample report withdrawing, blaming, or fighting as coping strategies under stress. Sloan and Cooper (1985) studied the stress-coping strategies reported by commercial airline pilots and found that they emphasized that the practical versus emotional forms of coping include the use of reason and logic and social support networks. The dominant stresscoping factors identified by Sloan and Cooper (1985) were the stability of the marital relationship and home life.

Stylistic coping processes of United States Army pilots were studied using a measurement of dispositional coping styles (Picano, 1990). Compared to a general population sample, and a sample of aircrew members and military personnel, the pilots were more given to active, problem-solving coping strategies. Also, these pilots displayed a greater proclivity to clarify matters with others, in times of stress. More importantly, pilots relied less on external emotional support, denial and withdrawing from stressors as coping tendencies. Thus, these coping tendencies appear to reflect differences in psychological predisposition independent from adaptation to the military or aviation environment.

Thus, the personality traits of pilots suggest that pilots typically have sufficient psychological resources for managing life stress. They are commonly described as being emotionally stable (i.e. low in neuroticism), a trait well suited to preventing acute stress from interfering with the performance of complex flight skills under intense time pressure. In general, the typical stress-coping styles of pilots emphasize mastery of problem situations through action-oriented strategies. In stressful situations, they tend to use more of externalizing and avoidant coping strategies than defense oriented strategies (Campbell \& O’Connor, 2010).

\section{Inadequate Stress Coping in Aviators}

Adaptability for military aviation comprises psychological/emotional suitability, motivation to fly, and ability to fly. All three factors are interrelated. An important aspect of psychological/emotional suitability is optimal stress coping skills, which are necessary for high-stress occupations. In aircrew, inadequate stress coping can affect aeronautical adaptability (US Department of the Navy, 2002). 
In addition to this, inadequate stress coping is known to influence health and recovery issues. Ursano (1980) reported that even though aviators are high in emotional stability when the stress threshold has been surpassed some form of externalizing response is seen, in which confrontation of unpleasant emotions is avoided, and the stress reaction is manifested as physiological or somatic complaints.

What more direct evidence of the role stress plays in aviation safety was provided by the United States Navy in two investigations (Alkov, Borowsky \& Gaynor, 1982; Alkov, Gaynor \& Borowsky, 1985). On personality, pilots who were held to blame for 'pilot error' accidents were seen as lacking in maturity, as having had a lack of self-awareness of limitations, and as being unable to recognize troublesome situations in advance. Pilots who were at fault in their mishaps evidenced observable behaviors which can be understood as representing maladaptive consequences of poor stress-coping. These included difficulties in interpersonal relationships, including marital as well as with superiors and peers, excessive use of alcohol, unprofessional flying, and a significant "change in personality." The study results give empirical evidence of the relationships between poor stress-coping and adverse pilot performance. The study also provides some clues to the early observable manifestations of poor stress-coping in pilots (i.e., "acting-out," externalizing or using avoidant coping mechanisms when forced to engage in emotion-focused coping). It suggests the potential for identifying pilots at increased risk for human error mishaps by predisposed susceptibility to stress or poor coping ability.

\section{Objective of Research}

The purpose of this research was to study which coping strategies are utilized by Indian military aviators because relatively little is known about this in the Indian context. Almost all research done on aircrew has been carried out in Western countries, and comparatively much less research has been done in Asian countries such as India. The question arises whether psychological concepts on aircrew which have been developed in the West can be merely duplicated and applied crossculturally. Different factors related to individualistic and collectivistic societies are most likely to influence findings in this area of research (Chun, Moos, \& Cronkite, 2006; Triandis, 1988).

It was hypothesized that there would be significant differences between observed and expected frequencies of prevalence in both problems solving and emotion-focussed coping patterns in Indian pilots. A secondary aim of this exploratory study was to observe whether these coping patterns would be different from patterns seen in previous Western studies on pilots. There are two main reasons why this could be so. First, studies suggest differences between Americans and Asians 
in stress coping (Bjorck, Cuthbertson, Thurman, \& Lee, 2001; Sinha \& Watson, 2007). Second, previous research from this laboratory indicates the possibility of cultural variations in Indian military pilots, on characteristics such as achievement, affiliation, and locus of control (Joseph \& Ganesh, 2006; Joseph \& Kochhar, 2011). Cultural differences could have an enormous bearing and implication for Indian aircrew especially in areas of pilot selection and training, technical issues like flying performance and flight safety and clinical matters such as in aircrew evaluation.

"Culture is best defined as a highly complex, continually changing the system of meaning that is learned, shared, transmitted and altered from one generation to another... This system of meaning encompasses the norms, beliefs, and values that provide prescriptions for behavior" (Chun, Moos, \& Cronkite, 2006). Various cultures have their unique elements and shared elements, and cultural values have been categorized to describe these. The four dimensions put forward by Hofstede (2001) are individualism/collectivism (I/C), power distance (PD), masculinity/femininity (MF), and uncertainty avoidance (UAI). These dimensions determine how people from different cultures interact within themselves and their societies. Individualism depends on the emphasis given to different values, attitudes, and behavior of the individual whereas in collectivism the importance is based on those within the group and not on the individual.

Western cultures are typically high in individualism, low on PD, characterized by masculine values, and low UAI. Individuals raised in such cultures adopt more active coping strategies because of lesser risks associated with directly challenging their environments, with an aim to usher in changes. In contrast, eastern collectivistic cultures have a high PD, are characterized by feminine values and high UAI. Individuals from this culture use more of emotion-focused coping skills due to a higher risk of retaliation for challenging others (Lui \& Spector, 2005). Understanding different cultures has implications for proactive global defense initiatives where air warriors often have to operate in diverse and multicultural environments. In such instances, there is often no time to deal with "culture shock" in addition to the most important stressors of combat and war.

\section{Method}

\section{Participants}

Ethical clearance for the study was obtained from the Institute Ethical Committee for Research. A sample of 160 Indian male military pilots consented to participate. They were from both an air force flying instructor school and from the Institute of Aerospace Medicine where pilots come to attend courses or for medical 
evaluation. The demographic characteristics of the sample were mean age, $30.18(s=$ 3.87), mean years of education $15.08(s=0.37)$, and mean years of service, $8.53(s=$ 3.95). Mean hours of flying was $1,416.29(s=871.69)$. Fifty percent of the sample was qualified flying instructors, and none had undergone critical incident stress management in the past.

\section{Instrument}

A demographic data sheet asked for information relating to personal history, flying history and medical history. Next, the Stress Coping Checklist (Rao, Subbakrishna, \& Prabhu, 1989) was administered. Conventional instruments developed for and on western pilots were intentionally not used for this purpose. The present choice was made because it had been drafted and validated on a normal Indian adult sample by Indian researchers (Rao, Subbakrishna, \& Prabhu, 1989). The questionnaire consists of 7 subscales which have been developed on an apriori basis. It comprises 70 statements relating to the everyday stress coping strategies an individual can use that are to be answered in such a way that a "Yes" response indicates that the subject uses that particular strategy often or frequently and a "No" response indicates that the subject uses that strategy infrequently or not at all.

Sample items in different scales are as follows. The Problem Solving scale has ten items examples of which include, you go over the problem again and again in your mind to try to understand it. There are five emotion-focused scales. DistractionPositive has 14 items. Illustrations of these are, to get away from things for a while, take a rest, or a vacation. Distraction-Negative has nine items such as make yourself feel better by smoking. Acceptance/Redefinition has 11 items, for example, accept it since nothing can be done. Religion/Faith has nine items, e.g. praying. Denial/Blame has 11 items with an example being, refusing to believe that something has happened. Finally, the Social Support scale has six items, e.g. seeking reassurance and emotional support from family members.

The score for each subscale was calculated as the total of the yes responses (scored as 1) on that subscale. The test-retest reliability is 0.74 , and the internal consistency (Cronbach's $\alpha$ ) ranges from 0.75-0.85.

\section{Procedure}

Tests were administered individually. Rapport was established with the pilot; voluntary informed consent was taken after which the demographic inventory and questionnaire were given to the individual for completion. The subjects were requested to complete the questionnaires as a part of a research study, which could 
have some implications for flight safety within the aviator community. They were given standard instructions for the test; were reminded to clarify all doubts with the examiner and answer all questions.

The test was then begun, and statements were answered on the same sheets. The results were hand scored according to the authors' instructions and converted to weighted scores and then percentages to facilitate comparisons. A Chi Square test was used first to see whether there was a significant difference in prevalence of different coping strategies and secondly to evaluate whether there were significant differences between observed and expected frequencies of prevalence/absence in individual coping strategy subscales.

\section{Results}

The descriptive statistics mean and standard deviation of raw weighted scores for the whole sample $(N=160)$ for all variables were: Problem Solving $\overline{\mathrm{x}}=7.00(s=$ 1.26), Distraction (positive) $\overline{\mathrm{X}}=6.56(s=2.52)$, Distraction (negative) $\overline{\mathrm{X}}=1.49(s=$ 1.38), Acceptance $\overline{\mathrm{x}}=7.36(s=1.95)$, Denial $\overline{\mathrm{x}}=2.86(s=2.11)$, Religion $\overline{\mathrm{x}}=1.82(s=$ 1.83), and Social Support $\bar{x}=3.22(s=1.40)$.

A Chi Square test was used first to see whether there was a significant difference in prevalence of different coping strategies. The percentage scores indicated the percentage of "yes" responses on that subscale and were taken to indicate prevalence. Chi Square analysis was done to see whether there were any significant differences between observed and expected frequencies of prevalence using the null hypothesis of equal probability; expected frequencies of prevalence for each of the seven coping strategies was $14.29 \%$. Analysis indicated a significant difference in prevalence of different coping strategies in this aviator group, $\chi^{2}(6)=22.52, p<.001$.

To understand the pattern of these differences, Chi Square values of the percentage frequency prevalence and absence were compared across seven coping strategies. The percentage scores indicated the percentage of "yes" responses on that subscale and were taken to indicate prevalence. The percentage of "no" responses was taken to indicate absence. Each of these individual subscales was then subjected to Chi Square analyses to evaluate whether there were any significant differences between observed and expected frequencies of prevalence/absence using the null hypothesis of equal probability; expected frequencies of prevalence and absence was $50 \%$ each. The Chi-Square values and significances for the seven different subscales were then compared. 
It can be seen from Table 1 and also Figure 1 that Indian aviators' most frequent prevalent stress coping strategy was Problem Solving $(70 \%), \chi^{2}(1)=14.40$, $p<.001$. This was in comparison to the frequency prevalence of the six other coping strategies subscales.

On the emotion-focused strategies, they had more frequent prevalence of three subscales significantly when these were combined, i.e. Acceptance (64\%), Social Support $(59 \%)$ and Distraction-positive $(48 \%)$. The additive value of these three subscales was $\chi^{2}(3)=6.78, p=.079$, indicating a trend towards significance. Results without the addition of individual subscale $\chi^{2}$ values were non-significant. The pilots had a relatively lower frequency of prevalence on Distraction- negative (15\%), Religion/Faith (21\%) and Denial/Blame (27\%). Differences among individual values were all significant, $\chi^{2}(3)=120.06, p<.001$.

\section{Discussion}

Indian aviators in our study were found to utilize problem-focused strategies most frequently when coping with stress. These findings are comparable with Picano (1990) who found that compared to a reference sample from the general population American pilots utilized more of active, problem-solving coping strategies, higher effective social support and were higher on acceptance. It appears that Indian aviators are similar to their American counterparts in all three respects.

Table 1

Individual and additive $\chi^{2}$ values of frequency prevalence and absence scores of different stress coping strategies in aviators.

\begin{tabular}{|c|l|l|l|l|l|}
\hline Variable & $\begin{array}{l}\text { \% Prevalence } \\
\text { Score }\end{array}$ & $\begin{array}{l}\text { \% Absence } \\
\text { Score }\end{array}$ & $\chi^{2}$ Value & $\begin{array}{l}\text { Additive } \\
\chi^{2} \text { Value }\end{array}$ & $\begin{array}{l}\text { Significance } \\
\text { One-tailed }\end{array}$ \\
\hline Problem Solving & 70 & 30 & 14.40 & - & $0.001(d f=1)$ \\
\hline Acceptance & 64 & 36 & 05.18 & & \\
\hline Social Support & 59 & 41 & 01.02 & 6.78 & $0.079(d f=3)$ \\
\hline $\begin{array}{l}\text { Distraction } \\
\text { (positive) }\end{array}$ & 48 & 52 & 00.58 & & \\
\hline Denial/Blame & 25 & 75 & 25.60 & & \\
\hline Religion/Faith & 21 & 79 & 36.86 & 120.06 & $0.001(d f=3)$ \\
\hline $\begin{array}{l}\text { Distraction } \\
\text { (negative) }\end{array}$ & 15 & 85 & 57.60 & & \\
\hline
\end{tabular}




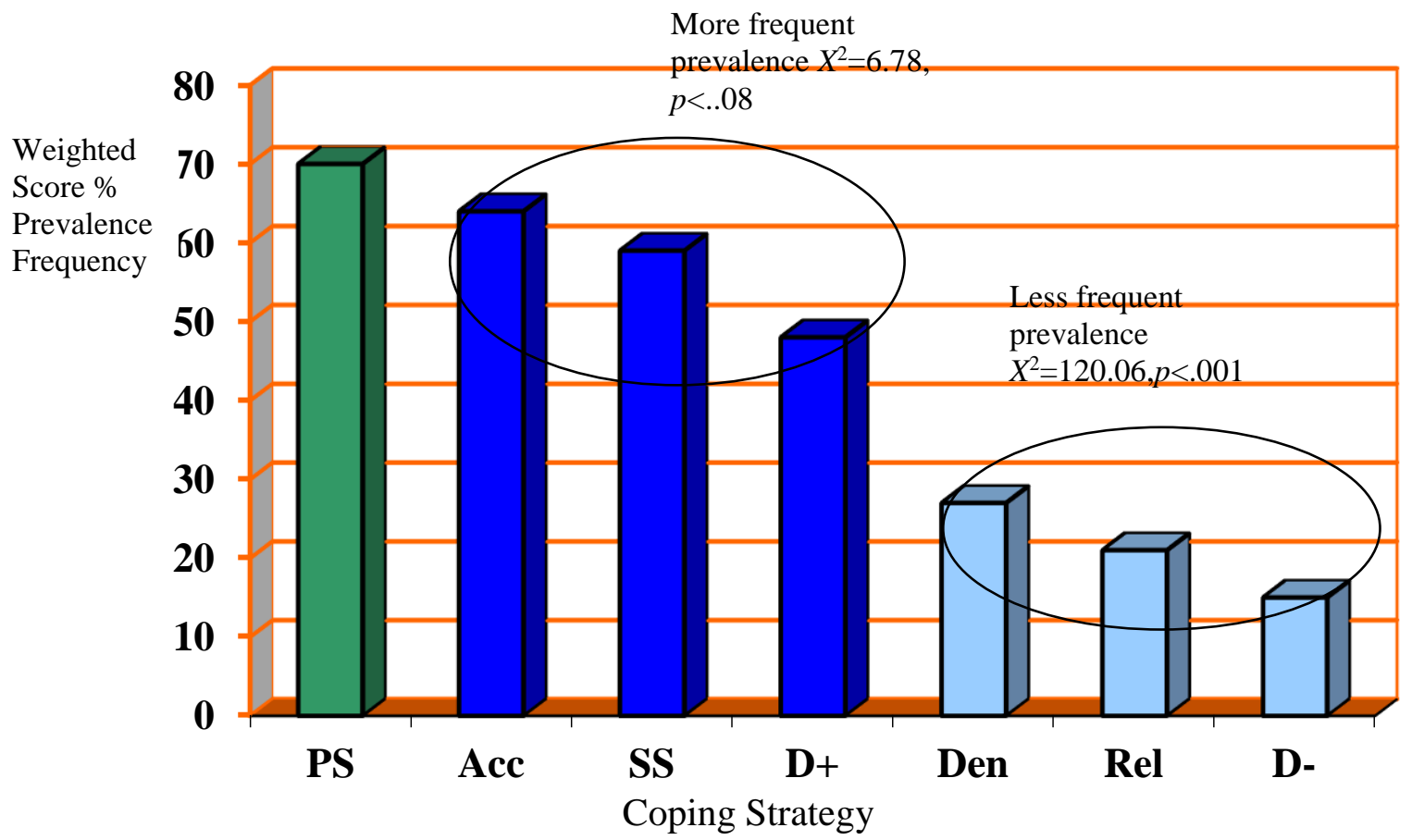

Figure 1. Percentage prevalence frequency of different stress coping strategies in aviators. Note $:$ PS $=$ Problem Solving, Acc $=$ Acceptance, $S S=$ Social Support, D $=$ Distraction, $\mathrm{Rel}=$ Religion, Den $=$ Denial

However, they seem to differ in that in addition to problem-focused strategies they also use emotion-focused strategies though these are utilized less frequently than Problem Solving. These emotions focussed strategies such as emotional, social support and positive distraction are both forms of avoidance. This tendency to also use emotion-focused strategies confirms a previous study on an Indian pilot clinical population (Taneja \& Joseph, 2007) which reported similar findings. However, because that sample consisted of pilots who had musculoskeletal disorders, a difference was seen in that those pilots also used religion as a prominent coping strategy, unlike in the present study.

Culture has a dominant influence on the environmental system and therefore also on the social climate. Individualistic societies such as the United States are different to collectivistic ones which tend to promote social conformity and interdependence. In individualistic persons, the target of control is likely to be external to the person; thus, they use much more of problem-focused methods to control the external environment. For collectivistic persons, the target of control is more self- 
oriented, because the individual needs to be part of the group and protect it. Thus, these individuals normally use emotion-focused strategies by trying to control their minds, emotions, thoughts, and behaviors (Chun, Moos, \& Cronkite, 2006).

This finding of the flexible use of both problem and emotion-focused methods in Indian pilots is also seen in other studies on the normal Indian population (Rao et al., 1989, Ahuja, 1996, Rupa, 2011). Though the patterns of coping may be similar, Indian pilots may still differ from the Indian male non-pilot sample, and this can be a topic for future research. Evidence of differential cultural coping patterns was found in a study by Bjorck et al. (2001). They reported that Korean and Filipino-American church attendees used both emotions- and problem-focused coping which differed from their Caucasian American counterparts who used more of problem-focussed coping.

The use of both problems solving and emotion-focussed coping could also be due to basic personality differences which may exist between eastern and western pilots. However, in the present study personality was not measured because significant differences in personality within the group were considered unlikely since personality assessment at selection level would result in homogeneity. Research from this laboratory has indicated that Indian pilots have higher Neuroticism and Agreeableness scores and lower Extraversion and Conscientiousness when compared to previous studies on western pilots (Joseph \& Kochhar, 2011). The 16 PF test was also administered on a sub-sample of 60 pilots in the present study. These results are reported elsewhere. Significant associations were found between Factor GConscientiousness with Problem Solving and Positive Distraction. Factors AOutgoing and I-Tender mindedness were related to Acceptance and Factor E (Assertiveness) was related to Social Support (Ayengar, 2008). It has been posited that personality factors are linked to coping skills (Meško et al...2009; Carver \& Connor-Smith, 2009). However, one limitation of the present study is that it has not verified this link. This area needs future investigation using the same personality and coping measuring instruments to evaluate whether coping differences are because of basic personality in culturally diverse pilot samples.

Our aviator group also indicated the most frequent prevalence of problem and emotion-focused social support coping. Social resources that are available to individuals can also be influenced by cultural context. In individualistic societies, the social network is likely to consist of only the nuclear family, some relatives, friends, and acquaintances (Triandis, 1988). Because of weaker distinctions between in and out groups, social networks tend to be vast and diverse, but wanting in emotional support. Collectivistic cultures have extended family networks, often without a clear 
boundary because of extensiveness and stronger emotional support (Chun, Moos \& Cronkite, 2006).

According to Chun, Moos, and Cronkite (2006) coping strategies may be influenced by two factors; appraisal and coping goals. They indicated that persons oriented towards individualism are more likely to evaluate stressors as a challenge, whereas those oriented towards collectivism are more liable to consider stressors as a threat. In our study, we found that pilots also tended to utilize positive distraction or avoidance. A more passive/avoidance coping could be resorted to by individuals from a collectivistic culture owing to their tendency to evaluate stressors as a threat. On the other hand, those from more individualistic cultures are likely to engage in more active or approach coping because of they may evaluate stressors as a challenge (Chun, Moos,\& Cronkite, 2006).

In a study by Sinha and Watson (2007), which compared Canadian university students with Indian students, a similar conclusion was drawn. They found that unlike Indians, the use of escape-avoidance coping predicted many psychological symptoms for Canadians. The escape-avoidance coping, a construct aligned with secondary control, had a higher prevalence in Indians in stressful conditions. This was attributed to the strong collective cultural orientation of Indians.

Coping goals are determined by cultural values and beliefs and they are different for individualism and collectivism (Chun, Moos, \& Cronkite, 2006). In individualistic cultures, the needs of the individual are given prominence, assertions are towards autonomy and independence, the external environment is controlled and gain is maximized. However in collectivistic cultures the needs of others are emphasized, relatedness and interdependence are reinforced, control is selfinternalized and loss is minimized.

Research on cultural differences provides a different perspective of military aviator attributes that might affect their job performance and aviation safety. One hundred and sixty military pilots were assessed on the Stress Coping Checklist. The results showed that Indian aviators do not differ from the Indian normal population in their general pattern of stress coping strategies. The results also revealed that Indian pilots' utilized flexible strategies with the use of more frequent emotion-focused stress coping strategies, unlike their western counterparts. The variance of stress coping strategies in Indian aviators compared with western aviators was explained as being due to a possible cultural difference.

Chun et al. (2006) posited a transactional model of five interactive systems (panels) to explain how culture can influence the stress and coping process. Panel four 
consists of cognitive appraisal and coping skills which interact with the preceding three panels- the environmental and personal systems in conjunction with the transitory conditions (stressors), which all work together to meet the demands of the stressors. The result determines panel five which is the health and well-being of the person. Future research efforts on aircrew need to measure all five aspects of culture utilizing large samples. One of the main limitations of this study is that information on stressors (major and minor life events) and behavioral outcomes such as flying performance were not evaluated. Differences in these variables could have affected individuals' perceptions and appraisals of stress.

Much of the western studies on stress and coping in aircrew have an individualistic value orientation which assumes that coping goals are set based on individual needs which if satisfied leads to a decrease in psychological distress. In these cultures, the emphasis is on meeting self-focused coping goals as opposed to satisfying the needs of others i.e. other focused coping goals.

The results of this study suggest that normative pilot data also needs to be culture specific. Such norms should be used when clinically assessing a pilot in conjunction with general population norms so that reliable and valid judgments are made. It also needs to be seen whether these clusters of emotion-focussed coping lead to higher psychological distress in pilots from collectivistic cultures as compared to individualistic ones. This has significant ramifications for psycho-diagnostics and therapeutic interventions in aircrew who display psychological/psychiatric consequences of stress and combat. Stress coping plays a pivotal role during treatment/interventions in disorders such as anxiety, fear of flying, motion sickness, PTSD or depression.

Military aviation training in India also has to take into consideration aspects of stress coping which can influence occupational performance (thought patterns, safety attitudes-internal threats which lead to undesirable aircraft states- aviation mishaps). This could call for organizations to place a greater responsibility on management to ensure that culture and CRM training are well integrated and represent a strong commitment to safety culture. The effectiveness of human factor training in both the civil and military have long been known to partly depend on cultural factors (Helmreich \& Merritt, 1998; Merritt, 1994; Soeters \& Boer, 2000).

In conclusion, the results of the present study show that Indian pilots utilize flexible stress coping strategies with the predominant use of problem-solving methods. Also, use of emotion-focused coping strategies showed a trend towards significance, unlike in their western counterparts. These findings need to be replicated and substantiated on larger sample sizes for clear-cut conclusions to be drawn. The 
variance of stress coping strategies in Indian aviators compared with western aviators may be explained as being due to a possible cultural difference. This may imply that cultural factors could influence stress coping and that this issue needs to be considered in both professional and clinical realms of future research investigations on aviators. 


\section{References}

Ahuja, J. (1996). Personality, coping style and psychological wellbeing in executives. M. Phil. Dissertation. Department of Clinical Psychology, National Institute of Mental Health \& Neurosciences (NIMHANS), Bangalore.

Alkov, R.A., Borowsky, M.S., \& Gaynor, J.A. (1982). Stress coping and the US Navy aircrew mishap. Aviation, Space, and Environmental Medicine,53, 1112-15.

Alkov, R.A., Gaynor, J.A., \& Borowsky, M.S. (1985). Pilot error as a symptom of inadequate stress coping. Aviation, Space, and Environmental Medicine, 56, $244-247$.

Ayengar, P. D. (2008). Aviation safety locus of control, stress coping and personality in Indian military pilots. M.D. Dissertation. Rajiv Gandhi University of Health Sciences, Bangalore.

Bjorck, J. P., Cuthbertson, W., Thurman, J. W., \& Lee, Y. S. (2001). Ethnicity, coping, \& distress among Korean Americans, Filipino Americans, \& Caucasian Americans. The Journal of Social Psychology, 14, 421-442. http://dx.doi.org/10.1080/00224540109600563

Campbell, J. S. \& O'Connor, P. E. (2010). Coping with stress in military aviation. In P.E. O'Connor \& J.V. Cohn (Eds), Human Performance Enhancement in High Risk Environments: Insights, Developments and Future Directions from Military Research. California: Greenwood Publishing Group, pp 169-188.

Carver, C. S., \& Connor-Smith, J. (2010). Personality and coping. Annual Review of Psychology, 61, 679-704.

http://dx.doi.org/10.1146/annurev.psych.093008.100352

Chung, M.C. (2006). Post-traumatic stress reactions following aircraft disasters. In R. Bor \& T. Hubbard (Eds.), Aviation Mental Health (pp.83-106). Surrey: Ashgate.

Chun, C., Moos, R.H., \& Cronkite, R. (2006). Culture: A fundamental context for the stress and coping paradigm. In Wong P.T.P.\& Wong L.C.J.(Eds), Handbook of Multicultural Perspectives on Stress and Coping. New York: Springer, pp29-53.http://dx.doi.org/10.1007/0-387-26238-5_2 
Cooper, C. L. \& Sloan, S. (1985). Occupational and psychosocial stress among commercial aviation pilots. Journal of Occupational Medicine, 27, 570-576. http://dx.doi.org/10.1097/00043764-198508000-00014

Department of the Navy. (2002). Manual of the medical department(MANMED), chapter 15, article 15-65. Washington, DC: U.S. Navy.

Dobie, T. G. \& May, J. G. (1994). Cognitive-behavioural management of motion sickness. Aviation, Space, and Environmental Medicine, 65(10), 1-20.

Fine, P. M. \& Hartman, B. O. (1968). Psychiatric strengths and weaknesses of typical Air Force pilots. Report No SAM- TR-68-121. Brooks Air Force Base, TX: USAF School of Aerospace Medicine.http://dx.doi.org/10.1037/e479742008-001

Folkman, S. \& Lazarus, R. S. (1980). An analysis of coping in a middle-aged community sample. Journal of Health and Social Behaviour, 21, 219-239. http://dx.doi.org/10.2307/2136617

Foreman, E. I., Bor, R., \& van Gerwen, L. (2006) Flight or Fright? Psychological approaches to the treatment of fear of flying. In R. Bor \& T. Hubbard (Eds.), Aviation Mental Health (pp. 69-82). Surrey, UK: Ashgate.

Fornette, M. P., Bardel, M. H., Lefrançois, C., Fradin, J., El Massioui, F.\& Amalberti, R. (2012). Cognitive-adaptation training for improving performance and stress management of air force pilots. The International Journal of Aviation Psychology, 22, 203-223. http://dx.doi.org/10.1080/10508414.2012.689208

Helmreich, R. L., \& Merritt, A. C. (1998). Culture at work in aviation and medicine. Aldershot, UK: Ashgate.

Hofstede, G. H (2001). Culture's consequences: Comparing values, behaviors, institutions and organizations across nations. (2nd Ed.). Thousand Oaks, CA: Sage Publications.

Holahan, C. J. \& Moos, R. H. (1987). Risk, resistance, and psychological distress: A longitudinal analysis with adults and children. Journal of Abnormal Psychology, 96, 3-13. doi: 10.1037/0021-843X.96.1.3 
Joseph, C. \& Ganesh, A. (2006). Aviation safety locus of control in Indian aviators. Indian Journal of Aerospace Medicine, 50, 14-21.

Joseph, C. \& Kochhar, R. R. (2011). Personality and motivational needs in Indian military pilots. International Journal of Applied Aviation Studies, 11, 3747.

Lui, C., \& Spector, P. E. (2005). International and cross cultural issues. In J. Barling, E. K. Kelloway, \& M. R. Frone (Eds.), Handbook of Work Stress (pp. 487 - 515). Thousand Oaks, CA: Sage Publications.

Meichenbaum, D. (2007). Stress Inoculation Training. In P. M. Lehrer, R. L. Woolfolk \& W. S. Sime, Principles and Practice of Stress Management (3rd Edition). (pp. 497-518). New York: Guilford Press.

Merritt, A. \& Helmreich, R. L. (1996). Human factors on the flight deck. The influence of national culture. Journal of Cross-Cultural Psychology, 27, 524.http://dx.doi.org/10.1177/0022022196271001

Meško, M., Karpljuk, D., Videmšek, M., \& Podbregar, I. (2009). Personality profiles and stress-coping strategies of Slovenian military pilots. Horizons of Psychology, 18 (2), 23-38.

Mitchell, J.T. (2006). Critical incident stress management in aviation: a strategic approach. In J. Leonhardt \& J. Vogt, Critical Incident Stress Management in Aviation (pp.13-42). Hampshire, UK: Ashgate.

Morse, J.S. \&Bor, R. (2006). Psychiatric disorders and symptoms among pilots. In R. Bor \& T. Hubbard (Eds.), Aviation Mental Health (pp.107-126). Surrey, UK: Ashgate.

Oyserman, D., Coon, H. M., \& Kemmelmeier, M. (2002). Rethinking individualism and collectivism: Evaluation of theoretical assumptions and meta-analyses. Psychological Bulletin, 128(1), 3-72. doi: 10.1037/0033-2909.128.1.3

Petrie, S. (2006). Early Interventions After Critical Incidents - Application. In Human Dimensions in Military Operations - Military Leaders' Strategies for Addressing Stress and Psychological Support (pp. 43-1 - 43-8). Meeting Proceedings RTO-MP-HFM-134, Paper 43. Neuilly-sur-Seine, France: RTO. 
Picano, J. (1990). An empirical assessment of stress-coping styles in military pilots. Aviation, Space, and Environmental Medicine, 61, 356 - 360.

Rao, K. (1997). Stress and coping: An overview. Seminar on Developments in Clinical Psychology, NIMHANS, Bangalore.

Rao, K., Subbakrishna, D.K. \& Prabhu, G.G. (1989). Development of a stress coping checklist-a preliminary report. Indian Journal of Psychiatry, 31(2), 128-132.

Rupa, R. (2011). A comparative study of stress and coping among parents of children with ADHD and parents of normal children. MSc. Dissertation. Rajiv Gandhi University of Health Sciences, Bangalore.

Sinha, B. K., \& Watson, D. C. (2007). Stress, coping and psychological illness: A cross-cultural study. International Journal of Stress Management, 14, 386397. doi: 10.1037/1072-5245.14.4.386

Soeters, J.L. \& Boer, P.C. (2000). Culture and flight safety in military aviation. The International Journal of Aviation Psychology, 10, 111-133. doi: 10.1207/S15327108IJAP1002_1

Sloan, S. \& Cooper, C.L. (1986). Pilots under stress. London: Routledge \& Kegan Paul.

Stahl, M.A. (2004). Stress, cognition and human performance: A literature review and conceptual framework. Report No. NASA/TM-2004-212824. Ames Research Centre, NASA, Moffet Field, CA.

Stetz, M., Thomas, M.L., Russo, M.B., Stetz, T.A., Wildzunas, R.M., McDonald, J.A., Wiederhold, B.K.\& Romano, J.A. (2007). Stress, mental health and cognition: A review of relationships and countermeasures. Aviation, Space, and Environmental Medicine, 78, B252-260.

Taneja, N., Joseph, C. (2007). Analysis of psychosocial factors which influence recovery in aircrew with musculoskeletal disabilities. (Departmental Project Report No. 199/4/2004), Institute of Aerospace Medicine, Bangalore. 
Triandis, H. C. (1988). Collectivism and development. In D. Sinha \& H. S. R. Kao (Eds.), Social Values and Development: Asian Perspectives. (pp. 285-303). Thousand Oaks, CA: Sage Publications.

Triandis, H. C. (1995). Individualism \& collectivism. Boulder, CO: Westview Press.

Ursano, R.J. (1980). Stress and adaptation: The interaction of the pilot personality and disease. Aviation, Space, and Environmental Medicine, 51, 1245 - 1249. 